\title{
Teaching the Middle East: Pedagogy in a Charged Classroom
}

Shanna A. Kirschner, Allegheny College

ABSTRACT Students in courses about the Middle East want to learn, and they crave discussion. Yet they enter the classroom with a set of beliefs about the region that interact with their fears of offending or contradicting their peers. Together, these can produce a classroom dynamic that ultimately stymies student learning. In this article, several strategies are described to ameliorate this concern. These range from short lessons that directly confront student biases about the Middle East, to close analysis of journal articles and empirical evidence, to structured debates and simulations, to specific classroom management techniques. Together, these strategies can promote engaged, lively debate; generate student self-awareness of their presuppositions; and enhance learning.

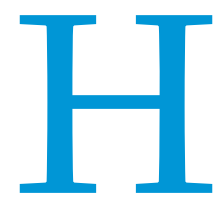

ow can we productively engage students in discussion of controversial international topics? Students crave knowledge on the Middle East, particularly following September 11; the American military involvement in Iraq, Afghanistan, and Libya; and the wave of protests and regime transitions beginning in late 2010. Students are especially driven to discuss-as opposed to passively listening to lectures on-the issues in the region. Students who may sit silently in the back of other classrooms become vibrant participants, engaging regularly and seriously with questions of terrorism, Islamist movements, or the Arab-Israeli conflict. Yet teaching courses that take advantage of and channel this enthusiasm presents unique challenges.

In this article, I identify and outline approaches to two distinct issues that characterize courses on the Middle East. First, students often enter the classroom with strong stereotypes, biases, and inaccurate information, including the notion that the Middle East is unique or exceptional. Correcting and overcoming these beliefs is vital to provide students with sound foundations on which to build their empirical and analytical skills.

Yet the process of examining student assumptions is hampered by a second challenge: many students do not express these beliefs for fear of offending or contradicting others, particularly those who they perceive as more expert. Students' perceptions of their peers have an especially pernicious effect when they view a course as covering particularly charged subject matter and believe their colleagues hold strong opinions about this material, as is true in many courses on the Middle East. Ultimately, this dynamic can generate an unproductive, unengaged, and even hostile environment.

The interaction of these two characteristics-students' biases and their perceptions of others' knowledge and biases-can stifle discussion entirely or limit it to only a few students, undermining

Shanna A. Kirschner is an assistant professor in the department of political science at Allegheny College. She can be reached at skirschn@allegheny.edu. learning. ${ }^{1}$ Students may even respond by dropping the course or failing to invest effort toward the class. Thus, instructors must find ways to correct stereotypes, engage students with the course material, and head off personal attacks and arguments that are likely to offend others. All of these strategies must not hinder future conversation.

Ample evidence shows that encouraging students' desire for active learning and in-class discussion improves both student interest and performance (Pollock, Hamann, and Wilson 2011; Powner and Allendoerfer 2008; Shellman and Turan 2006). As instructors, this necessitates surrendering some control, which can be daunting. Indeed, colleagues frequently comment in horror that, "This must be such an uncomfortable class to teach"; "Don't they just yell at each other all the time?"; and "How on earth do you manage discussions in that class?".

The literature on political science pedagogy offers little guidance for responding to these questions, focusing instead on specific strategies, such as simulations, role-playing, policy briefs, case studies, or structured debates (e.g., Krain 2010; Omelicheva 2006; Powner and Allendoerfer 2008; Raymond 2010; Sasley 2010; Siegel and Young 2009). Although these are an important part of instruction and engagement in any active-learning situation, these focus attention on a limited number of classes during the semester. There is little direction toward a broader pedagogical approach across several months of instruction, particularly with respect to facilitating in-class discussions.

Literature on teaching race, gender, and other controversial topics offers some illumination. However, while most students have engaged with issues of race at some point in their lives, whether in their home community or on campus, this is not necessarily the case in courses on the Middle East. These studies do translate well in their emphasis on preexisting student biases and understanding students' backgrounds (e.g., Martin 2010; Saunders and Kardia n.d.). Nuts-and-bolts articles also offer useful exercises to help students overcome these challenges and to foster 
productive discussions (e.g., Alex-Assensoh 200o). Indeed, some of the techniques in this article are adapted from more general discussion of charged classrooms to the specific context of courses on the Middle East (e.g., Pace 2003).

In the following discussion, I briefly elaborate on each challenge and introduce several strategies that can foster discussion given these dynamics. Throughout the article, I offer examples from four classes ranging from the introductory to advanced seminar levels: Government and Politics of the Middle East, The ArabIsraeli Conflict, War and Peace in the Middle East, and Democracy and Authoritarianism in the Middle East. I use a mix of lectures, discussions, take-home essays, group exercises, case studies, structured debates, simulations, and research projects in each course. In this article, I focus on the techniques that best foster robust discussion and provide students with the empirical, theoretical, and analytical tools to understand regional politics, even in an emotionally charged setting.

\section{SOUND FOUNDATIONS?}

What do students believe is true about the Middle East? Most students possess strong views on Middle Easterners and on life and politics in the region including the common perception that the Middle East is somehow unique. Previous education, the media, or the experiences of acquaintances all may influence these beliefs. Students' views may be quite fixed, even for students who acknowledge that they know little about the region. While some of these impressions are accurate or may be grounded in fact, these are just as often inaccurate. arises with respect to other security issues and to the role of Islamists. Although undergraduate students may not need to embed themselves in the area studies debate, the belief that Middle Easterners are uniquely irrational or that simply being in the region promotes abnormal behavior inhibits students' learning and analysis. ${ }^{2}$ For instance, if students understand the Lebanese, Iraqi, and Yemeni civil wars as a simple result of the entire region being unstable, then it is unlikely that we will discuss broader issues of power-sharing, institutional design in divided societies, or the links between resources and conflict.

Thus, teaching about the region requires working within the constraints of exploring and challenging students' beliefs about the Middle East. Indeed, much of the task in introductory courses on the region is akin to "myth-busting." The first step is to acknowledge and explore the conventional wisdom; I often use news articles or YouTube clips about the region to do this. Then, I ask students to raise their hands if they believe the presented view to be generally accurate. This exercise establishes a starting point for discussion by identifying one type of belief and articulates what many students may believe, without singling out any individuals (Ambrose et al. 2010). As Angelo and Cross (1993) note, this also facilitates a pre- and postassessment of student learning for a given section of the course.

Students often respond well to a myth-busting approach if it is clear that the goal of these discussions is to evaluate the conventional wisdom: perhaps we will accept it, but we should only do so after careful consideration. Combining several strategies is useful at the next stage. First, we explore alternate perspectives. Analyt-

\section{Thus, teaching about the region requires working within the constraints of exploring and challenging students' beliefs about the Middle East. Indeed, much of the task in introductory courses on the region is akin to "myth-busting."}

Why does this matter? At the most basic level, correcting errors and raising student self-awareness of their presuppositions promotes learning (Ambrose et al. 2010). A seemingly simple misconception, however, also can influence deeper learning and analysis: for example, the erroneous claim that Israel is at war with all its neighbors shapes our understanding of regional politics and these states' foreign policies. It also must be corrected before we can ask interesting questions about patterns and variation across the region. For instance, why did peace processes between Israel and Egypt and Jordan produce treaties while that with Syria has not?

Other student impressions stem from more than a simple factual error: for example, the belief that [all] Muslims support antiWestern violence or conceptions of all women throughout the region as cloistered by a set of repressive and deadly state and family institutions. In the first case, this belief makes it difficult to explore, for example, whether poverty and education influence support for terrorism, as many people believe. In the second case, we might want to understand how cultural legacies vary between Morocco and Saudi Arabia; why religious institutions play different roles in shaping policy throughout the region; or the strategies women employ to campaign for office in Iran, Iraq, and Jordan.

The belief in Middle Eastern exceptionalism seems particularly acute regarding the Arab-Israeli conflict yet also frequently ical articles and peer-reviewed books that devote explicit attention to alternative explanations, providing evidence for and against perspectives, facilitate discussion. ${ }^{3}$ Close summary and a brief discussion of one or two pieces can identify some of the contending claims and begin the process of evaluating each. ${ }^{4}$ In lower-level courses, where students may not be comfortable with peer-reviewed journal articles, the underlying theories can be explained without asking students to read the original article.

Second, I employ both intra- and interregional comparisons to promote nuanced analysis. I assign individual students to be "country experts," tasked with evaluating each analytical issue we explore in a specific context. As they brief each other throughout the semester, they learn that many stereotypes are based on one or two examples, but may not be more widely representative. For instance, Islamist movements in Morocco, Egypt, Syria, and Turkey have interacted with the state and with the people in very different ways. Indeed, individual movements within some of these states sharply diverge from each other in both goals and strategies. As students better understand patterns throughout the Middle East, they can critically evaluate the conventional wisdom against the empirical record.

Cross-regional comparisons also foster critical examination of beliefs. The instructor could ask students to compare the regionwide protests that began in late 2010 to political participation 
they have observed in other contexts, including in the United States. Or, students could use Iraqi elections to evaluate the effectiveness of gender-based quotas as opposed to other strategies for empowering female candidates; or they could review regional examples to explore how different voting systems shape electoral outcomes. These types of discussions engage and draw on the expertise of students who are interested in European or American politics, for instance. These also relate to larger conversations in the field and begin to familiarize first- and second-year students with the benefits and drawbacks of different methodologies.

Third, I ask students to explore a wide range of views to promote more sophisticated analysis. In introductory classes on the region as a whole, I assign students two to four short stories and editorials from Israeli and Palestinian authors. ${ }^{5}$ Understanding the wide political spectra in both communities helps students avoid treating each as a monolith (a common perspective of many students). When I teach a semester-long course on the conflict, we explore these perspectives in much greater detail, reading columns and speeches by David Grossman, Amira Haas, Sari Nusseibeh, Mahmoud Abbas, Binyamin Netanyahu, Avigdor Lieberman, Ismael Haniya, and Ariel Sharon. Simulations also can help students grapple with different actors' interests and beliefs.
East is uniquely strange and therefore not amenable to analysis. Watching and reading documentaries and first-hand accounts helps students effectively examine their beliefs. When possible, guest speakers from the region often are the most compelling authorities for students. Drawing parallels-admittedly sometimes a bit strained-also helps students to question their assumptions (Ambrose et al. 2010). Many students become especially engaged in debating whether Islamist parties are analogous to actors in the United States who oppose the current application of Church-State boundaries.

After examining students' beliefs about the region, discussion can move in many directions. Some instructors might find it important to explore why specific myths and beliefs about the Middle East are common. This could draw on our understandings of the media, public opinion, and framing. Or, the class might address underlying intellectual, historical, or cultural trends that drive our beliefs, such as Orientalism and colonialism. These discussions can incorporate coursework outside political science and promote interdisciplinary thinking. In other classes, students might delineate the empirical implications of different foundational beliefs. For example, how does our understanding of women's status influence our analysis of political voice and protest? Or, how did policy

\section{Finally, putting a human face on issues and making the foreign more familiar also breaks down the belief that the Middle East is uniquely strange and therefore not amenable to analysis. Watching and reading documentaries and first-hand accounts helps students effectively examine their beliefs.}

Comparing extant theories to the Middle East (and viceversa) helps students explore the idea of Middle East exceptionalism. For example, students could assess and apply the literature on coups to Egypt and Syria, comparing how the sub-Saharan African or Latin American experience relates to the Middle Eastern one. ${ }^{6}$ Ultimately, students see that coups do not necessarily occur just because the Middle East is always in turmoil; rather, similar economic and political dynamics produce similar effects in Fiji, the Central African Republic, or Argentina. In discussing the evolution of the Arab-Israeli conflict, I first introduce different lenses of ethnic conflict, such as primordialism, constructivism, and instrumentalism. Then, students evaluate each approach's insights into the conflict's early development. This strategy allows students to explore whether Israelis and Palestinians fight simply because they are different or because particular patterns of behavior exacerbated tension. Similarly, using strategic models of deterrence and crisis bargaining helps students understand the 1956 and 1967 wars in more sophisticated ways than "Arabs and Israelis just hate each other, so why wouldn't they fight?" Students can see, then, how theories that help us to understand Hindu-Muslim riots in India or the Cuban Missile Crisis also can illuminate Middle Eastern conflicts. Exercises like these ultimately help students become better analysts in other political science courses, as well. They develop and practice comparative and analytical skills by learning to critique theories and explore alternative explanations.

Finally, putting a human face on issues and making the foreign more familiar also breaks down the belief that the Middle makers' image of Iraq and of regional relations influence the steady escalation of tensions in 2002 and early 2003 ? If the United States had seen Saddam Hussein as a rational leader who could be deterred from using weapons of mass destruction, would invasion still have been inevitable? Under what conditions could the course of events have been changed??

\section{FEAR OF OFFENDING?}

Creating a respectful classroom climate is essential to fostering honest and engaged discussion. Students need to know that they can take intellectual risks without being attacked or mocked for their views. This is not an easy task. On one hand, most students in a given class do not have direct experience with the region. On the other hand, a small number of students do have personal, direct connections with the Middle East. At some institutions, these include family members-or the student-who have served in the military overseas. Members of Middle Eastern or Jewish diaspora communities comprise a proportion of the student body at other institutions. On the first day of class each semester, I distribute a survey asking students to rate their knowledge of the Middle East on a five-point scale. I use the results to show students that most of them consider themselves novices and should feel confident in their abilities relative to their peers. Yet those students who have little experience in the region continue to feel intimidated by those who express strong perspectives that still seem, to the students, authoritative. The fears of contradicting those who "know what they're talking about," offending other students, or being drawn into a heated debate with those who live in the same dorm, play 
on the same sports team, or eat in the same dining hall can undermine students' confidence and engender deep stress over a course. Indeed, my office hours in the early weeks of the semester seem almost exclusively filled by students grappling with anxiety about classroom dynamics in courses on the Middle East.

Addressing these fears constitutes a vital balancing act: students should learn to simultaneously question and defend their beliefs. Thus, the task may be, more accurately, to foster an environment in which students feel able to develop those skills, and in which their anxiety about doing so does not become counterproductive. By the end of the semester, in surveys, most of my students indicate that they notice significant improvement in their ability to analyze current events, to critique multiple perspectives, and to understand political developments. Moreover, they demonstrate significantly increased confidence during the semester, volunteering answers more often and engaging increasingly often in both large and small-group discussions. The following strategies can help to create that environment.

A productive activity for the first day of class is to have students collectively develop a set of ground rules for discussions. These guidelines should emphasize the importance of practices such as listening to others and discussing ideas rather than attacking individuals. The possibility of such ground rules breaking down provokes significant anxiety among some faculty. So, how can one prevent an especially heated debate, or even a shouting match, from sabotaging the rest of the semester? Sometimes students will realize the implications of an assertion within a few moments
Lesson and activity planning also influences the likelihood of such exchanges. Including a wide range of activities and working with both large and small groups bolsters students' comfort (Ambrose et al. 2010). Larger groups of 15 to 20 afford some anonymity, while discussions between three or four students familiarize individuals with their colleagues' personalities and backgrounds. This makes expressing controversial perspectives at least a little less threatening.

An especially important practice that I reinforce in crafting discussion and exam questions is to focus on analytical, rather than emotional, questions. These may cover exactly the same ground, but students accord more legitimacy to alternative viewpoints if they are framed as evaluating an argument. In exploring the ArabIsraeli conflict, for instance, we focus on the implications of each side's evidence for its claims about the Palestinian refugee exodus in 1948-49. Students embed themselves in the competing narratives through a structured debate; we then build on this discussion to explore the implications of these contrasting narratives for current policy. ${ }^{8} \mathrm{~A}$ writing or discussion exercise examining terrorism might start from the assumption that it is rational or directed to a specific end. Then, asking students to look for evidence that this assumption is true (or not) frames the discussion in less emotional terms that promote the use of evidence to support claims and make tearful shouting matches less likely.

Requiring students to identify and evaluate an alternative to every argument they make can also foster analytical skills. This counterargument should be the best possible point they can make,

\section{Allowing students to step back from their own opinions and consider the question from others' perspectives also helps students focus on arguments, rather than individuals.}

and clarify their remarks, ameliorating tensions. Other students may also challenge them.

However, because the instructor should not sanction offensive (rather than just controversial) remarks or personal attacks, a brief reminder of the ground rules is often appropriate. Many students respond better if confrontational behavior is addressed using the third person or a short period of time after an incident has occurred. In this way, the instructor can productively distance an incident from an individual student, so that he or she does not feel "shamed" in front of the class-but nonetheless, usually recognizes his or her own behavior enough to avoid it in the future. For instance, a recent in-class discussion on torture devolved from a discussion of US military policy to a diatribe against military personnel. Two normally engaged students with family or significant others currently in the military overseas appeared deeply uncomfortable and did not participate in the discussion at all-quite rare for those individuals. I asked students to stop for a minute and brainstorm how the existence and form of laws of war might influence states' behavior in similar situations. After discussing this question, I reviewed the main points and reminded the students to be respectful of each other. Without identifying any individuals, I pointed out that a number of the students' colleagues had family in the military. These students all looked deeply relieved and returned to their normal level of engagement in the next class; subsequent discussions of the topic focused on policy questions and institutional approaches, rather than condemning individuals. not a strawman. A similar version of this exercise would ask students to examine what has to hold for each claim they make to be true (Ambrose et al. 2010).

Allowing students to step back from their own opinions and consider the question from others' perspectives also helps students focus on arguments, rather than individuals. Several of the strategies I previously discussed facilitate this. Comparing journal articles and multiple voices on a single issue in either the academic or popular literature opens space for students to critique perspectives with less fear of offending their peers. For instance, when we discuss the US invasion of Iraq and subsequent sectarian violence, we pair readings from popular nonfiction, magazines like Foreign Affairs, and academic journals. ${ }^{9}$ Each offers different ideological and analytical perspectives on the conflicts; together they provide a multifaceted view that enables students to craft analytical claims supported by empirical evidence.

Structured debates and simulations also facilitate this goal, particularly if positions are assigned. Students can then examine the strengths and weaknesses of different arguments with the plausible deniability that they hold an "assigned" position. Angelo and Cross (1993) argue that this type of exercise also can foster the ability to make ethical choices, hone leadership skills, and develop advanced arguments. In the course I teach on the ArabIsraeli conflict, I assign each student a political actor to role-play throughout the semester. We conduct a series of short (45 to 50 minute) negotiations on each of the final status issues, and then 
complete the semester with a two-class-period simulation of an international peace conference.

Finally, close classroom management also can prevent intense discussions from escalating to the point where feelings are hurt and students become unengaged for the remainder of the semester. The order in which we call on individuals can affect the content of a discussion; this can be a matter of balancing both points of view and personalities. Simple strategies such as restating a potentially inflammatory comment or reframing an observation to examine the underlying issue also can redirect discussion to a productive end. For example, when a Christian Lebanese-American student in one of my courses began arguing that Muslims simply could not be trusted and were inherently violent, asking students to think about and then discuss the political implications of this belief led to a robust exploration of how stereotypes influence intrastate conflict. Challenging students to identify and then explore terrorism with no connection to the Middle East-as in Northern Ireland, Sri Lanka, Peru, or Germany-both contests the underlying assumption that Islam is uniquely violent and allows for a broader discus- they enter the classroom can interact with their fears of offending or contradicting others, particularly those who they perceive as more expert. In conjunction, these can produce a classroom dynamic that ultimately stymies student learning.

I employ several approaches to ameliorate this concern. These range from "myth-busting" lessons, to more subtle evaluations of journal articles and empirical evidence, to structured debates and simulations, to specific classroom management techniques. Although this article is not an exhaustive discussion, I believe my suggestions will be useful for both novices and experienced instructors of courses on the Middle East. These strategies can promote engaged, lively debate; generate student self-awareness of their presuppositions; and make the classroom less charged and more conducive to learning.

\section{ACKNOWLEDGMENTS}

I am grateful to Brian Harward, Rachel O'Brien, and Bruce Smith for especially insightful comments and suggestions on earlier versions of this article. Any errors are my own.

\section{Paying close attention to the direction of a conversation allows instructors to step in at key moments to redirect the discussion or to break rising tension. Simply asking for perspectives from other students can deescalate when a heated debate between two or three students is beginning.}

sion of terrorism as a tool of political violence. Students also often argue that Islam is inherently incompatible with democracy. Asking the class to explain politics in Turkey and Indonesia sparks a conversation about specific political institutions as well as about political culture as an analytical framework.

The quintessential "That's an interesting perspective. How do you think critics might respond?" also can deescalate a heated discussion. This strategy can be done in an even more structured manner using published debates and empirical data. When students consider the role of women in the Middle East, we begin with an open discussion and then pair case studies with large-n work to explore those hypothetical critics' views. I often focus this exercise on two questions: (1) variation in the status and roles of women in (for example) Lebanon, Saudi Arabia, Morocco, and Iran and (2) the implications of broader or narrower women's rights for regime type.

The instructor often treads a fine line between respecting students' contributions to discussion and knowing when to interrupt. Paying close attention to the direction of a conversation allows instructors to step in at key moments to redirect the discussion or to break rising tension. Simply asking for perspectives from other students can deescalate when a heated debate between two or three students is beginning. When this approach might interrupt the flow of a conversation, keep a "queue" of hands on the board. Asking students to take a minute to reflect on the discussion and jot down their reactions allows for some breathing space, as well, and helps engage others in the debate.

\section{CONCLUSION}

Students in courses on the Middle East want to learn, and they crave discussion. Yet the set of beliefs about the region with which

\section{NOTES}

1. See Ambrose et al. (2010) for further discussion of the relationship between classroom climate and student learning.

2. See Haklai (2009) and Tessler, Nachtwey, and Banda (1999) for discussion of the area studies debate and the Middle East.

3. The rich literature on terrorism is especially good for this type of exercise. Three articles I often assign are Kavanagh (2011), Tessler and Robbins (2007), and Walsh and Piazza (2010).

4. Students often find polling data especially compelling evidence. As an added benefit, a robust discussion frequently ensues about the validity of survey instruments as students identify which questions are especially effective, and why researchers ask certain questions.

5. The Bitterlemons forum (www.bitterlemons.net) is an especially rich source for opinion pieces by Israelis and Palestinians.

6. I use Belkin and Schofer (2003) as a reference for this exercise.

7. One starting point for this discussion might be Walt and Mearsheimer (2003).

8. The discussion in Tessler (2009) provides a good framework for this discussion.

9. I regularly use selections from Packer (2006), Dawisha (2008), and blog posts from Juan Cole (www.juancole.com) and Foreign Policy (mideast. foreignpolicy.com).

\section{REFEREN CES}

Alex-Assensoh, Yvette. 200o. "Minority Politics Courses: Moving beyond Controversy and Toward Active Learning." PS: Political Science and Politics 33 (2): 201-06.

Ambrose, Susan A., Michael W. Bridges, Michele DiPietro, Marsha C. Lovett, and Marie K. Norman. 2010. How Learning Works: Seven Research-Based Principles for Smart Teaching. San Francisco: Jossey-Bass.

Angelo, Thomas A., and K. Patricia Cross. 1993. Classroom Assessment Techniques: A Handbook for College Teachers, 2nd edition. San Francisco: Jossey-Bass.

Belkin, Aaron, and Evan Schofer. 2003. “Toward a Structural Understanding of Coup Risk. Journal of Conflict Resolution 47 (5): 594-620.

Dawisha, Adeed. 2008. "The Unraveling of Iraq: Ethnosectarian Preferences and State Performance in Historical Perspective" Middle East Journal 62 (2): 219. 
Haklai, Oded. 2009. "Authoritarianism and Islamic Movements in the Middle East: Research and Theory-Building in the Twenty-First Century." International Studies Review 11: 27-45.

Kavanagh, Jennifer. 2011. "Selection, Availability, and Opportunity: The Conditional Effect of Poverty on Terrorist Group Participation" Journal of Conflict Resolution 55 (1): 106-32.

Krain, Matthew. 2010. "The Effects of Different Types of Case Learning on Student Engagement." International Studies Perspectives 11: 291-308.

Martin, Kathleen J. 2010. "Student Attitudes and the Teaching and Learning of Race, Culture, and Politics." Teaching and Teacher Education 26 (3): 530-39.

Omelicheva, Mariya Y. 2006. "Global Politics on Trial: Using Educational Debate for Teaching Controversies of World Affairs." International Studies Perspectives 7: 172-86.

Pace, David. 2003. "Controlled Fission: Teaching Supercharged Subjects." College Teaching 51 (2): 42-45

Packer, George. 2006. The Assassins' Gate. New York: Farrar, Straus and Giroux.

Pollock, Philip, Kerstin Hamann, and Bruce Wilson. 2011. "Learning through Discussions: Comparing the Benefits of Small-Group and Large-Class Settings." Journal of Political Science Education 7 (1): 48-64.

Powner, Leanne, and Michelle Allendoerfer. 2008. "Evaluating Hypotheses about Active Learning." International Studies Perspectives 9: 75-89.

Raymond, Chad. 2010. "Do Role-Playing Simulations Generate Measurable and Meaningful Outcomes? A Simulation's Effect on Exam Scores and Teaching Evaluations." International Studies Perspectives 11: 51-80.
Sasley, Brent E. 2010. "Teaching Students How to Fail: Simulations as Tools of Explanation." International Studies Perspectives 11: 61-74.

Saunders, Shari, and Diana Kardia. n.d. "Creating Inclusive College Classrooms." University of Michigan Center for Research on Learning and Teaching. Available at http://www.crlt.umich.edu/gsis/P3_1.php.

Shellman, Stephen M., and Kürşad Turan 2006. "Do Simulations Enhance Student Learning? An Empirical Evaluation of an IR Simulation.” Journal of Political Science Education 2 (1): 19-32.

Siegel, David A., and Joseph K. Young. 2009. "Simulating Terrorism: Credible Commitment, Costly Signaling, and Strategic Behavior." PS: Political Science and Politics 42 (4): 765-71.

Tessler, Mark. 2009. A History of the Israeli-Palestinian Conflict. 2nd edition. Bloomington: Indiana University Press.

Tessler, Mark, Jodi Nachtwey, and Anne Banda, eds. 1999. Area Studies and Social Science. Bloomington: Indiana University Press.

Tessler, Mark, and Michael Robbins. 2007. "What Leads Some Ordinary Arab Men and Women to Approve of Terrorist Acts against the United States?" Journal of Conflict Resolution 51 (2): 305-28.

Walsh, James, and James Piazza. 2010. "Why Respecting Physical Integrity Rights Reduces Terrorism" Comparative Political Studies 43 (5): 551-77.

Walt, Stephen M., and John J. Mearsheimer. 2003. “An Unnecessary War.” Foreign Policy 134: 50-59. 